\title{
The Design and Implementation of Production Management Information System Based on B/S
}

\author{
Peng Zhang \\ Information Engineering Department, Tianjin Bohai Vocational Technology College, TianJin, P.R.China \\ zhangpengei@163.com
}

\begin{abstract}
s-this paper took the practical situation of some manufacturing enterprise in Tianjin as the basis of system demand to design and develop the overall framework and the function of various modules by analyzing and studying its internal management process and business process. Then this paper determined to apply SQL Server to conduct list structure design, adopt the current popular $\mathbf{B} / \mathrm{S}$ framework as the system framework, take Visual Studio.NET 2008 as the development tool and combine HTML, CSS, C\# languages to conduct the system implementation process after fully understanding the characteristics of various frameworks. The system function is basically conform with the system design requirements after testing conformation, which not only achieve the information exchange and sharing among various internal departments as well as between internal and external enterprises, but shows the promotion of management information system on enterprise management and production.
\end{abstract}

Keywords: production management information system; ASP.NET; B/S structure; relational data base;

With the rapid economic development and increasing market competition, the manufacturing enterprises are confronted with more and more pressure. Meanwhile, due to the larger enterprise scale, it becomes urgent to introduce a set of enterprise management information system with complete function that is suitable for our enterprise's working process and contents.

This topic research aims to conduct unified storage, processing and analysis on Tianjin Jinda actuator Co., Ltd by applying computer, network and database technology. The production management information system developed according to the business requirements of Tianjin Jinda actuator Co., Ltd is beneficial to achieving its standardization, production automation, decision intelligence, marketing precision, management networking; to reduce raw material consumption and inventory cost, decrease production cost and capital occupation by proper resources allocation; the production management information system enables to comprehensively analyze customer's requirements, properly arrange the order production and help the information communication among various departments.

\section{ENTERPRISE BUSINESS PROCESS}

The customer of this system is Tianjin Jinda actuator Co., Ltd. The developed production management system at this time aims to manage the business operation and business authorization of three departments in the company including raw material warehouse, machining workshop and semifinished product warehouse. At present, the company mainly relies on Excel spreadsheet to handle and share business data, while the staff completely depend on manual data recording, which shares huge workload, baldness and error-prone. The enterprise system business process can be obtained in the figure 1 by detailed understanding, analysis and conclusion.

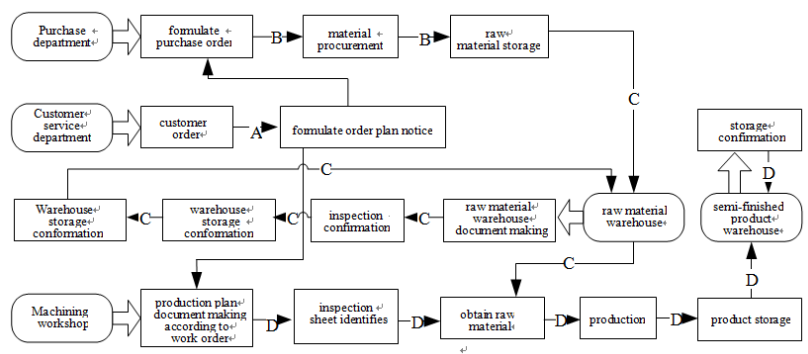

Figure one Enterprise business process

Purchase department--formulate purchase order--material procurement --raw material storage

Customer service department-customer orderformulate order plan notice-storage confirmation

Warehouse storage conformation-warehouse storage conformation-inspection confirmation-raw material warehouse document making - raw material warehouse semi-finished product warehouse

Machining workshop-production plan document making according to work order-obtain raw materialproduction-product storage

The figure includes five departments including purchase department, customer service department, raw material warehouse, machining workshop and semi-finished product warehouse. However, the practical operation in the production management system only manages three departments including raw material warehouse, machining workshop and semi-finished product warehouse.

This main business process starts with the customer service department. The customer service department formulates the production plan notice (as access A in the figure 1) according to the customer order. Then the purchase department ascertains the materials, specification and quantity and formulates the purchase order according to the plan notice and inventory information. At last, put the purchased materials into raw material warehouse (as access $\mathrm{B}$ in the figure 1). The raw material warehouse shall include all the materials into inventory after document making, inspection confirmation and warehouse confirmation (as access $\mathrm{C}$ in the figure one). The machining workshop 
formulates the specific production plan and work order according to the production plan notice, add detailed procedure on work order and then obtain the needed raw material for production in the raw material warehouse after confirming the work order inspection (obtaining the material belongs to out warehouse of raw material, which also needs product out records and inspection confirmation, as access $\mathrm{C}$ in the figure one). Further, the enterprise will put into production and then put the products into the warehouse after the completion of production (as access D in the figure 1).

\section{SYSTEM FUNCTION REQUIREMENT}

The basic system demand can be included as follows by analyzing the enterprise business process, investigating on various departments and communicating with managers.

This system includes four modules: raw material warehouse management, machining workshop management, semi-finished product warehouse management, other system managements.

\section{A. Raw material warehouse management:}

Raw materials' in and out management; inventory management: the highest and lowest inventory management as well as stocktaking management;

\section{B. Machining workshop management}

Production plan entering (Note: not production plan management); production work order management; machining worker piecework management;

\section{Semi-finished product warehouse management:}

Semi-finished product warehouse's in and out management; inventory management; inventory alarm management and stocktaking management.

\section{D. other system managements:}

System management (the authorization setting and role assignment of system user, data backups, login history records); basic data management (raw material, semifinished product, finished product, suppler, employee, department etc); comprehensive enquiry statistics.

\section{SYSTEM OBJECTIVE DESIGN}

The system is divided into 12 modules according to the analysis of requirements and design for module separately is introduced as follows:

\section{A. Functional integrity}

Functional integrity is the most basic requirement of system. The system function shall contain the previously analyzed production management business and process operational usability

\section{B. Ease of operation}

The operational usability is mainly presented on the following aspects:

1) Easy installation and deployment. Can not expect production manager share very high computer application level. The installation, deployment and backup of system shall be simple and easy using.

2) Friendly interface. The excellent interface enables to reduce faulty operation and wrong data. Hence, the interface shall lean close to Windows style that is familiar to everyone.

\section{System security}

The production information shall be accurate, timely and confidential. The system security is rather important. Therefore, we shall not only improve the system security from design and coding perspectives, but provide business security for some important operations (such as inspection confirmation, warehouse confirmation).

\section{MIS intelligence}

This system shall break though the function of traditional MIS system and analyze production inventory situation from the current large number of data to provide early warning function, offer reference information for decision-making level and enhance the system intelligence.

\section{SYSTEM STRUCTURE DESIGN}

The system function can be divided into five main modules based on the above system framework design according to the production process demand of manufacturing enterprise. Then the five main modules can be divided into eleven sub-modules according to the operation authorization and operation accessibility. Every sub-module completes the work with same nature that also belongs to the same category on the operation authorization. The specific functions of eleven sub-modules are as follows, which appears with the most bottom menu to complete the whole function of this system. The system module structure, see figure 2. The detailed functions of eleven sub-modules will not be further described elaborately.

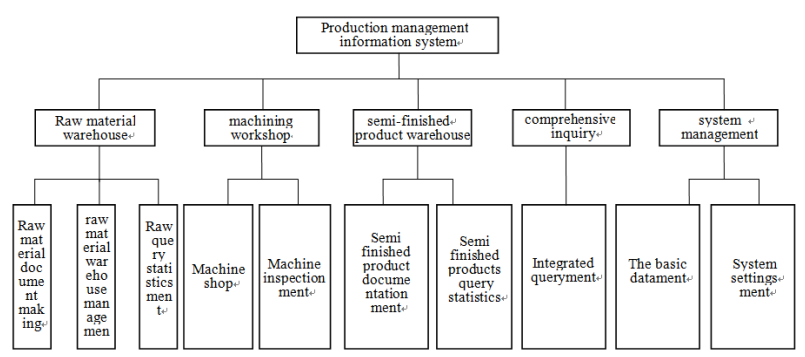

Figure two system modular structure

Production management information system

Raw material warehouse machining workshop semifinished product warehouse comprehensive inquiry system management

Raw material document making raw material warehouse management raw material inquiry statistics machining workshop machining inspection semi-product document making comprehensive inquiry basic data system setup 


\section{SPECIFIC IMPLEMENTATION OF SYSTEM}

After the completion of program requirement analysis and system design, the next main task means to apply professional development programming tool to achieve the system operation process and function module according to the completed system framework and function module.

This system mainly adopts the combined ASP.NET and JAVASCRIPT scripting language to carry out development. The ASP.NET with large number of server controls enables to achieve the data interaction. The JAVASCRIPT enables to formulate various webpage effects such as pop-up window, prompt message, show and hide page elements, page input validation etc. The application of JAVASCRIPT enables the webpage program to stimulate the operation effect alike the client program for users' convenience.

The management information system takes the computer the tool based on the database system. The relational database Microsoft SQL Server database is adopted here.

The system totally builds more then 40 data sheets with rather complex relations including staff basic information sheet, customer basic information sheet, supplier basic information sheet, raw material basic information sheet, product basic information sheet, production plan sheet, raw material and product in and out records sheet etc. To properly design the structures of those data sheets is the guarantee for successful and efficient application. The readwrite and enquiry efficiency of large number of data shall be fully considered at the time of building those sheets.

The numerous codes of system implementation will not be listed in detail. Instead, we will only introduce the design standards.

\section{A. general layout of management function}

The friendly operation interface and excellent layout will leave a deep impression on the customers. Meanwhile, the humanized design enables to bring out more professional system. The layouts of this system are as follows: the upper part is system BANNER and main module navigation bars and the left part is the sub-function of every module. The layout of this interface is basically similar to that of the majority of application software and application system, which enables the administrator to conduct the operation of various functions conveniently. The left function area keeps the same at the time of clicking the corresponding functional module navigation. Only the right interface display shares partial changes.

\section{B. friendly user prompts}

The system will pop up the prompt box through AVASCRIPT at the time of clicking the operational button to hint the corresponding results. When the login times out, the system will directly pop up the time-out information to hint the user for repeated operation. When the user enters the

\section{REFERENCES}

[1] Xue Huacheng, Management Information System [M]. Beijing: Tsinghua University Press, 2006. wrong information, the system will pop up the prompt box to hint user for wrong entered information. When the user clicks to conduct deletion operation, the system will firstly ask user whether to conduct the deletion or not. If the user clicks for confirmation, the program will then continue the operation. The system will also hint whether the deletion is achieved after deleting the information.

\section{C. normalization of code and data}

The application of standard naming rule enables to achieve standardized management at the time of naming the various sheets and webpage to search for the corresponding handling program with visual document names and maintain the program at the same time. According to the length of table fields, to limit the input word length of the corresponding controls on the webpage and then carry out the further validation on the server enables to prevent the input overflow effectively.

\section{D. program exception handling mechanism}

We shall consider the program exception and introduce exception handling mechanism in program segment during program design process. Therefore, the existing problems can be found out through the exception handling to guarantee the normal operation of program after exception. Meanwhile, the database roll-back mechanism shall also be introduced to roll back the existing problems during database operation to its initial condition.

The exception handling and data roll-back can not only guarantee the normal operation of the program, but ensure the database can restore to its primary condition at the time of errors so as to ascertain the accuracy of the data.

\section{E. code structure modularization}

The object-oriented design method as well as three-tier architecture method is adopted. The code structure can be divided into data access layer, logical processing layer and data presentation layer according to its module definition, which will present clearer modular and help the further maintenance and double-layer development.

\section{CONCLUSION}

This system has begun to function well in the enterprise daily work. The well operation not only improves the communication and information sharing ability among departments, but changes the management and operation principle of managers. Besides, the system also improves the work efficiency of employees and provides accurate information for managers to make rapid production judgment. However, this system exist some shortcomings on design and implementation, which will be improved during the later maintenance phase to satisfy the needs of enterprise development.

[2] Tang Wei, The Research on design and development technology of management information system based on NET: [master thesis]; 2005.06

[3] Zheng Zengliang, ASP.NET Program Design Guide, Xi'an Jiaotong University Press, 2006 